\title{
Diagnostic difficulties in the detection of spinal osteoblastoma in a child
}

\author{
Małgorzata Skuza', Teresa Stachowicz-Stencel ${ }^{2}$ \\ 'Diagnostic Imaging Department, Institute of Maritime and Tropical Medicine, Medical University of Gdansk, Poland \\ ${ }^{2}$ Department of Paediatrics, Haematology and Oncology, Medical University of Gdansk, Poland
}

\begin{abstract}
We describe a case of a 15-year-old boy with low back pain that progressed and subsequently developed into unilateral lower limb numbness. An X-ray study was inconclusive, but a CT study showed a vertebral body mass with intravertebral space narrowing. An additional MRI study displayed compression of the spinal roots. The child demanded surgical management. A histological examination from the excised tumour revealed osteoblastoma.
\end{abstract}

\section{KEY WORDS:}

spine tumour, osteoblastoma, low back pain.

\section{INTRODUCTION}

Osteoblastoma (OTB) comprises $1 \%$ of bone tumours. The commonest site of its appearance is the spine. The majority of patients are adolescents and young adults, with male predominance. Osteoblastoma in most cases grows as an expansile lesion, which may induce pain and neurological deficits. Low back pain can be a presentation of various conditions. If the pain does not subside, imaging investigation should be conducted.

\section{CASE REPORT}

We present a case of a 14-year-old male patient with progressive low back pain. The pain occurred two years prior to the diagnosis. A lumbosacral spine $\mathrm{X}$-ray revealed narrowing of L4/L5 and L5/S1 intervertebral spaces (Fig. 1A and 1B). He denied any trauma history or excessive sport activity. The patient was managed by symptomatic treatment. Over the following months he manifested stiffness and tingling of his left lower limb. Another X-ray study was ordered, and it showed a slight progression of the L5/S1 intervertebral space narrowing. Next, a computed tomography (CT) scan was performed where destruction of the L5 vertebral body caused by a focal lesion with an osteolytic change was noticed (Fig. 2A). The lesion occupied the left L5 pedicle and the left transverse process. The dorsal part of the destructed vertebral body protruded into the spinal canal and caused its narrowing. The study presented signs of left intervertebral foramen narrowing at the L5/S1 level. A magnetic resonance imaging (MRI) scan was required for additional research, and it showed that the lesion appeared hypointense in T1- and T2-weighted images with marked post-contrast enhancement (Fig. 2B and 2C). Minor compression of the left S1 nerve root was noted. The patient was admitted to the Department of Paediatrics, Haematology, and Oncology at the Medical University of Gdansk.

On admission, the child was in a good clinical condition. His vitals were within normal limits. Laboratory tests from blood and urine were normal, with no increased levels of tumour markers. The spine at the site

\section{ADDRESS FOR CORRESPONDENCE:}

Małgorzata Skuza, Diagnostic Imaging Department, Institute of Maritime and Tropical Medicine,

Medical University of Gdansk, Powstania Styczniowego 9B, 81-519 Gdynia, Poland, fax +48 58 6998506,

e-mail: skuza.malgosia@gmail.com 

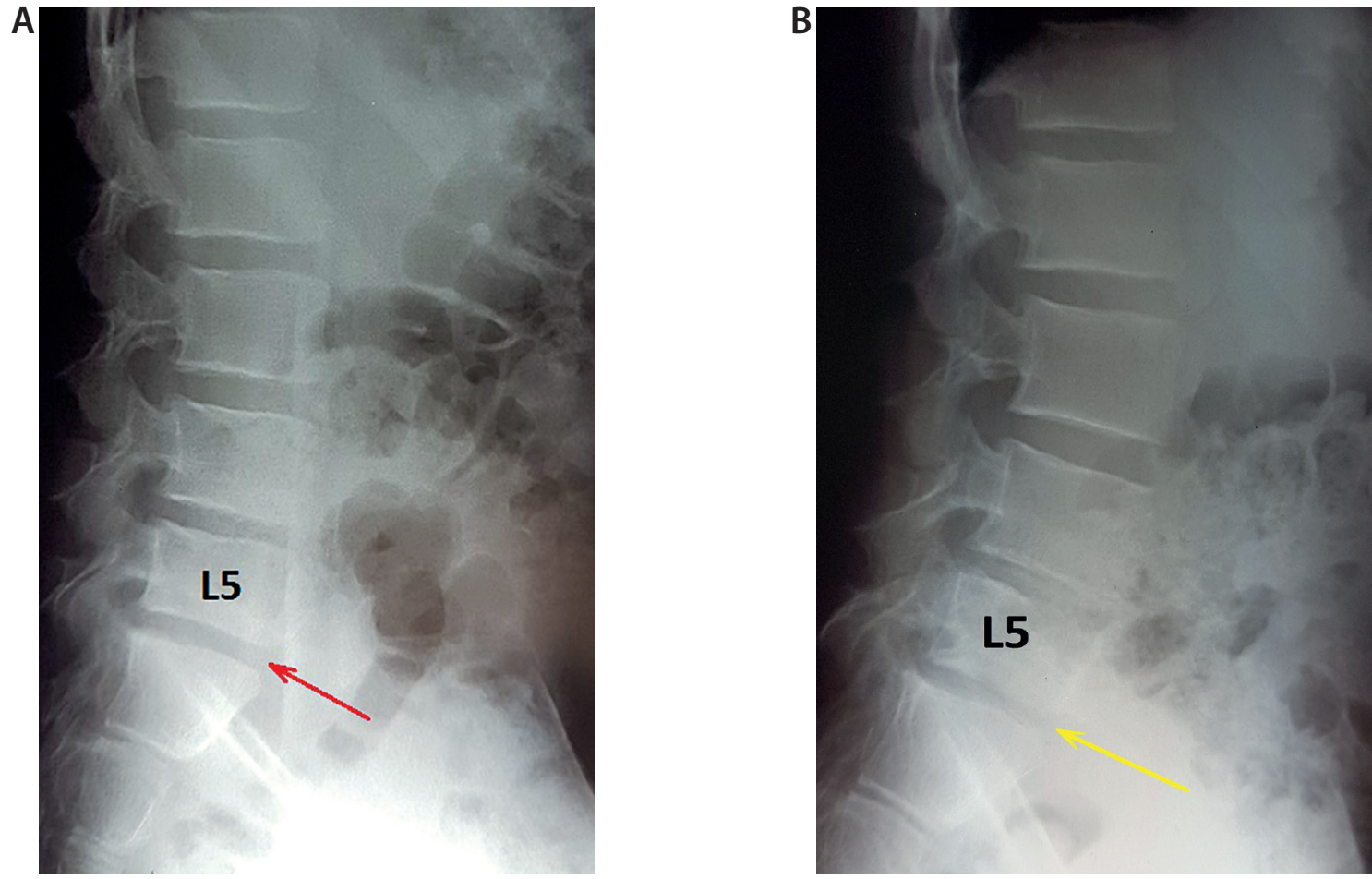

FIGURE 1. A) A lumbosacral X-ray study in the lateral projection shows narrowing of the L4/L5 and L5/S1 (red arrow) intervertebral spaces. B) A study performed a few months later displays progression of the latter (yellow arrow)

of the tumour presented distortion, and the skin above was tender. A neurological examination revealed positive tension signs of the left lower limb.

The patient demanded surgery to stabilise the L5 and S1 vertebrae for decompression. An open biopsy was performed as a first procedure for histological examination, with subsequent L3-S1 transpedicular stabilisation. The specimen did not show any tumoural growth, but it was noted that the diagnosis cannot be stated as final. Another surgery was essential to excise the tumour. The neurosurgery team removed the majority of the L5 vertebral body by the anterior approach. They chose the transperitoneal access. Subsequently, a DePuy Spine L5 vertebral body prosthesis was inserted. The surgery proceeded as planned.

A histological examination from the removed lesion revealed osteoblastoma with some components of aneurysmal bone tumour. The study was verified in another independent pathology department, which confirmed the diagnosis.

After two months a follow-up an MRI scan was performed, which demonstrated a minor focal enhancement in the L5 vertebral body, which represented tumour remnants. The patient's clinical status was good, his symptoms resolved completely. Another MRI scan was ordered after three months and it showed no progression. The boy was referred to the outpatient clinic in good condition.
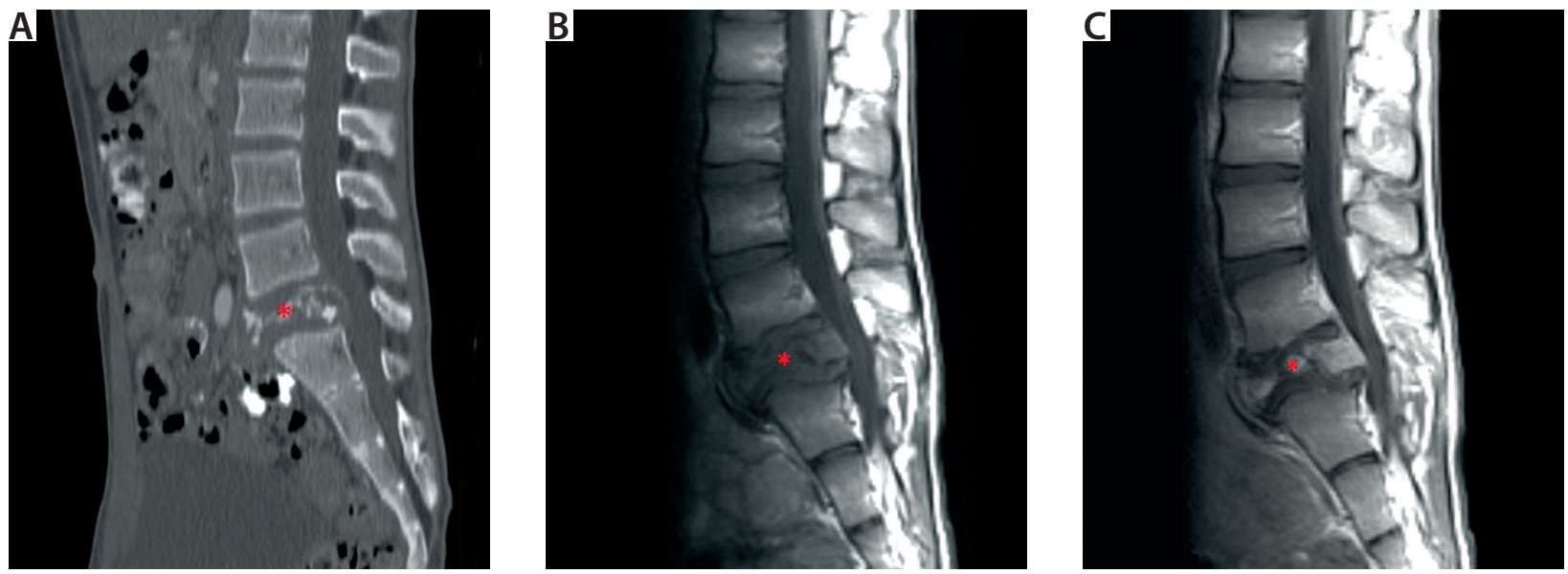

FIGURE 2. A bone window CT study in sagittal reformat (A) shows a narrowed L5 vertebra (asterisk) with osteolytic change, extending to the spinal canal. A T1-weighted imaging MRI study before (B) and after (C) gadolinium administration presents a hypointense L5 lesion (asterisk) with post-contrast enhancement 


\section{DISCUSSION}

Osteoblastoma (OTB) is a benign tumour. It typically affects young people and it has a predilection to male gender. The tumour develops in every bone and the commonest side of its appearance is the spine [1]. It may coexist with other osseous tumours, in $15 \%$ with aneurysmal bone cyst $(\mathrm{ABC})$ [2]. The clinical presentation of OTB depends on the tumour location. Pain is the dominant symptom, but in the early stages of backache evaluation a neoplastic disease is rarely considered in the differential diagnosis [3].

The most common causes of prolonged low back pain in children are spondylolysis, Scheuermann's disease, sacroilitis, poor posture, and rarely infectious disease [4]. Neoplastic bone pains may result from primary bone tumours, including osteosarcoma and Ewing's sarcoma, other neoplasms infiltrating bony structures, bone metastases, or disorders commonly involving the skeletal system (e.g. Langerhans cell histiocytosis). The commonest causes of bone metastases are neuroblastoma, soft tissue sarcomas, germ cell tumours, and malignant hepatic tumours. The skeleton may be infiltrated by malignant haematological cells, such as leukaemia and lymphoma $[5,6]$.

Spinal OTB is likely to grow expansively, which can cause protrusion into the spinal canal and compression of the spinal cord and the spinal nerves. This may lead to neurological deficits. $\mathrm{ABC}$ is a lesion of an unknown nature, with a suggested neoplastic character [7]. It affects mainly patients under 20 years of age. The imaging studies show $\mathrm{ABC}$ as a cystic lesion in an expanded bone [8].

Imaging features of OTB are non-specific. An X-ray study shows a radiolucent lesion with fine margins [9]. In our case, the only radiographic feature noticed was narrowing of two intervertebral spaces. Computed tomography $(\mathrm{CT})$ characterises more precisely the tumour's structure, whether it is lytic or blastic. The most frequent pattern is an expansile tumour with sclerotic margins and variable internal calcifications. Magnetic resonance imaging (MRI) helps to evaluate the involvement of surrounding soft tissue and neural elements. The OTB signal is low to intermediate in T1-weighted images and low to high in T2-weighted images. An additional component of ABC, which was a predominantly cystic growth, complicated the diagnosis in our patient.

Confirmation of OTB can be achieved only by a histological examination from a biopsied specimen.

Surgical resection of the tumour is the primary treatment, with total excision shown to have the best overall outcome [10]. Radiotherapy and/or chemotherapy may be required as adjuvant treatment in cases of a non-complete resection of the tumoural mass. OTB has a good prognosis; the recurrence rate is $15-20 \%$ [11]. Our patient did not demand any additional treatment.

This case shows that a neoplastic mass is rarely considered in a differential diagnosis in early stages of low back pain evaluation. OTB is a rare tumour with nonspecific imaging features. It requires several imaging studies for precise diagnosis. Narrowing of the intervertebral space shown on an X-ray study as a sole sign may be acknowledged as a non-neoplastic discopathy.

\section{CONCLUSIONS}

Osteoblastoma is a rare cause of low back pain in children. Every case of spinal abnormalities displayed on an X-ray image, followed by patient's worsening afflictions, should prompt further investigation studies.

\section{DISCLOSURE}

The authors declare no conflict of interest.

\section{REFERENCES}

1. Li Z, Zhao Y, Hou S, et al. Clinical features and surgical management of spinal osteoblastoma: a retrospective study in 18 cases. PLoS One 2013; 8: e746.

2. Ravindra VM, Eli IM, Schmidt MH, Brockmeyer DL. Primary osseous tumors of the pediatric spinal column: review of pathology and surgical decision making. Neurosurg Focus 2016; 41: E3.

3. Rodriguez DP, Poussaint TY. Imaging of Back Pain in Children. AJNR Am J Neuroradiol 2010; 31: 787-802.

4. Houghton KM. Review for the generalist: evaluation of low back pain in children and adolescents. Pediatr Rheumatol Online J 2010; 8: 28.

5. Drożyńska E, Połczyńska K, Bień E, et al. Guzy lite kręgosłupa i kanału kręgowego u dzieci. Przyczyny i konsekwencje opóźnień rozpoznania. Med Wieku Rozwoj 2004; 2: 183-191.

6. Stachowicz-Stencel T, Bień E. Bone pains in malignant disorders in children. Fam Med Prim Care Rev 2007; 3: 859-861.

7. Mankin HJ, Hornicek FJ, Ortiz-Cruz E i wsp. Aneurysmal bone cyst: a review of 150 patients. J Clin Oncol 2005; 23: 6756-6762.

8. Bivins E, Alidina JA, Bancroft LW. Aneurysmal bone cyst involving the C2 vertebra. Orthopedics 2015; 38: 78-143.

9. Galgano MA, Goulart CR, Iwenofu H, et al. Osteoblastomas of the spine: a comprehensive review. Neurosurg Focus 2016; 41: E4.

10. Boriani S, Amendola L, Bandiera S, et al. Staging and treatment of osteoblastoma in the mobile spine: a review of 51 cases. Eur Spine J 2012; 21: 2003-2010.

11. Lucas DR. Osteoblastoma. Arch Pathol Lab Med 2010; 134: 14601466 